Journal of Advanced Research in Fluid Mechanics and Thermal Sciences

\title{
Numerical Study of Shell and Tube Heat Exchanger Performance Enhancement Using Nanofluids and Baffling Technique
}

\author{
Lahcene Bellahcene ${ }^{1, *}$, Djamel Sahel ${ }^{2}$, Aissa Yousfi ${ }^{3}$ \\ Laboratoire de Mécanique, Université Amar Telidji-Laghouat, Algeria \\ Laboratoire des Carburants Gazeux et Environnement (LCGE), UST-Oran-MB, Algeria \\ Laboratoire d'études et Développement des Matériaux Semi-conducteurs et Diélectriques, Université Amar Telidji-Laghouat, Algeria
}

\section{ARTICLE INFO}

\section{Article history:}

Received 27 September 2020

Received in revised form 20 December 2020

Accepted 20 December 2020

Available online 15 February 2021

\section{Keywords:}

Nanofluid; heat transfer; Baffle; shell;

heat exchanger

\section{ABSTRACT}

The aim of this work is to investigate the forced convective heat transfer phenomena and fluid flows of water-based $\mathrm{Al}_{2} \mathrm{O}_{3}$ nanofluids in the baffled shell and tubes heat exchanger (STHE). Water as a hot fluid flows in the side of the tubes, and $\mathrm{Al}_{2} \mathrm{O}_{3}$ nanofluids as cooling fluid flow in the shell side. Numerical investigations have been carried out based on the continuity, momentum, and energy equations which are solved by using the finite element method with the help of the COMSOL 5.4 CFD software. The obtained results were presented by average Nusselt number, streamlines, isotherms, and various physical parameters which are a volumetric fraction of nanoparticles $(1 \% \leq C v \leq 3 \%)$. The obtained results reveal an increase in the heat transfer with the rise of inlet velocity and volume fraction, where the Nusselt numbers are augmented by $0.1 \%, 3.96 \%$ and $7.62 \%$ for $\mathrm{Cv}=1 \%, 2 \%$ and $3 \%$, and the friction factor are increased by $22.41 \%, 24.14 \%$ and $26.72 \%$ for $\mathrm{Cv}=1 \%, 2 \%$ and $3 \%$ compared with base fluid respectively. In addition, the presence of baffles inside tubular heat exchangers can create a better mixture of fluids which is augmenting heat transfer execution. The choice of these parameters is important to get the maximum improvement of heat transfer with minimum entropy consumption.

\section{Introduction}

The shell-and-tube Heat exchangers (STHEs) are important equipment that are mostly used in many engineering processes such as electric power generation, air-conditioning, petroleum refineries, natural gas processing, refrigeration, and nuclear power systems [1-4]. The multi-function services and application options provided by the STHEs make this device an important element that plays an essential role in these industrial processes. In this field, the looking for their processes of

\footnotetext{
* Corresponding author.

E-mail address: I.bellahcene@lagh-univ.dz
}

https://doi.org/10.37934/arfmts.80.2.4255 
thermo-hydraulics enhancement present an important point and essential factor in all followed strategies to rationalize and conserve the energy consumption $[5,6]$. Likewise, the choice of suitable type of STHEs based on the better construction materials, where the improper selection causes undesirable operation and equipment failure [7].

Where, the diversity of STHEs types presents more factors to test seriously the material of construction to avoid any problem [8,9]. In addition, the shape geometry, number, and size of baffles, the working fluid presents some parameters to design the heat exchanger. These parameters directly influence the hydro-thermal mechanisms and performances of the STHEs [10-12]. According to the massive development of thermal systems, conventional fluids like air and water do not become a suitable solution in the heat transfer field. The main problem in using these fluids is the low thermophysical properties. Where, the convective heat transfers depending on the thermophysical properties of fluids such as thermal conductivity, viscosity, density, and heat capacity. Recently, nanofluids have been given a very good solution to the convective heat transfer field. The nanofluid is a suspension of nanoparticles in a basic fluid. The addition of metallic nanoparticles to the basic fluids like water and alcohol considerably develops the convective heat transfer behavior of nanofluids. Simply, the high thermal conductivity of the nanofluids becomes a promising strategy which is merits to use in the design of the heat exchangers.

In the time of nanotechnology, researchers have discovered and developed the governing laws of the thermophysical properties of nanofluids which are explain and understand the fundamental mechanisms of fluids heat transfer in existing nanofluids [13-16].

Numerous studies on shell-and-tube heat exchangers have been shown high heat transfer coefficients in using nanofluids. Shahrul et al., [17] analytically studied the thermal performance of a shell-and-tube heat exchanger by using nanofluids of four different types of nanoparticles: $\mathrm{Fe}_{3} \mathrm{O}_{4}$, $\mathrm{ZnO}, \mathrm{TiO}_{2}, \mathrm{CuO}$, and $\mathrm{Al}_{2} \mathrm{O}_{3}$. They reported that the maximum heat transfer coefficient is observed in the case of $\mathrm{Al}_{2} \mathrm{O}_{3}$-water suspension. Unfortunately, and from literature, there is not an exact decision on the suspension of the most effective nanofluids, where several researchers have reported some contradiction [18-20].

Farajollahi et al., [21] experimentally studied of two types of nanofluids $\left(\mathrm{Al}_{2} \mathrm{O}_{3}\right.$ and $\left.\mathrm{TiO}_{2}\right)$ in a shelland-tube heat exchanger under turbulent flow conditions. They described that $\mathrm{TiO}_{2}$ nanofluids have a better heat transfer rate than that $\mathrm{Al}_{2} \mathrm{O}_{3}$ nanofluids. Al Nahian et al., [22] performed an experimental analysis to study conjugate heat transfer in a microchannel heat exchanger. They used $\mathrm{CuO}$-water, $\mathrm{Al}_{2} \mathrm{O}_{3}$-water, and $\mathrm{Al}_{2} \mathrm{O}_{3}$-ethylene glycol. Their results depicted that the basic fluid of nanofluids causes a significant effect on heat transfer coefficients $[23,24]$.

Fares et al., [25] experimentally exploited the graphene/water nanofluid in order to improve the performance of a vertical STHE. They reported that the mean thermal efficiency of the heat exchanger was improved by $13.7 \%$ in using graphene/ water nanofluid. Currently, Salem [26] employed Multi-Walled Carbon Nanotube (MWCNT)/water nanofluid or cold pure water. In his experiment, he used horizontal shell and semi-circular tubes (SCTs) heat exchanger of a counter-flow configuration, and MWCNT volume concentration $(0 \leq \varphi \leq 0.5 \%)$. They observed that MWCNT volume fraction of $\phi=0.5 \%$ ensures better thermal performances. In addition, he proposed correlations to predict the heat transfer coefficient and pressure drop.

The combination between magnetite ferrofluid flow and an external magnetic field can improve the performance fin-and-tube compact heat exchanger (FTHEs) [27]. Bezaatpour et al., [28] tested the effets of rotary tubes and mahnetic-included nanofluid on heat transfer behaviors of a FTHE. They gounded that empoying eatch method separly can rise the peak heat transfer coefficient by further than $60 \%$. In order to improving the hydrothermal and exergetic performance of heat exchangers, Bezaatpour and Rostamzadeh [29] numerically conducted a study to analazing hydrothermal and 
entropic carateresitics of $\mathrm{Fe}_{3} \mathrm{O}_{4} /$ water ferrofluid under the effet the magnetic field. They reported that the existence of magnetic field, the thermal and exergy efficiences rise up to $90 \%$ and $33 \%$ repectively.

Therefore, the majority of researchers have been advised that the classical techniques such as the insertion of baffles inside STHXs don't become a better solution to reduce the energy cost [3033]. The combination between the baffled channels heat exchangers and nanotechnology can improve the performance of the thermal systems. For this purpose, the present study is carried out to study hydro-thermal characteristics of baffled shell-and-tube heat exchanger using nanofluids. $\mathrm{Al}_{2} \mathrm{O}_{3}$ /water nanofluid for three different concentration of $\mathrm{Al}_{2} \mathrm{O}_{3}$ nanoparticles were used (i.e. $C_{v}=$ $1 \%, 2 \%$ and $3 \%$ ). The investigations were conducted by using the CFD code COMSOL Multiphysics, $v$. 5.4. The obtained results show that the combination between the nanofluids at high concentration and the baffles inserts can considerably improve the performance of STHEs.

\section{Details of the Geometrical Model}

Figure 1 shows the geometry of the shell-and-tube heat exchanger mode used in this study, the hot fluid flows in the side of tubes, while the cool fluid flows in the shell side in a counter-current configuration. The tubes are arranged in a rotating triangular arrangement. More details are listed in Table 1.

Table 1

Geometric dimensions of shell and tube heat exchanger

\begin{tabular}{ll}
\hline Parameter & Value \\
\hline Inner and outer diameter of tubes & $15 \mathrm{~mm}$ \\
Inner and outer diameter of shell & $100 \mathrm{~mm}$ \\
Shell diameter & $200 \mathrm{~mm}$ \\
Number of tubes & 37 \\
Number of baffles & 4 \\
Shell and tube length & $500 \mathrm{~mm}$ \\
\hline
\end{tabular}

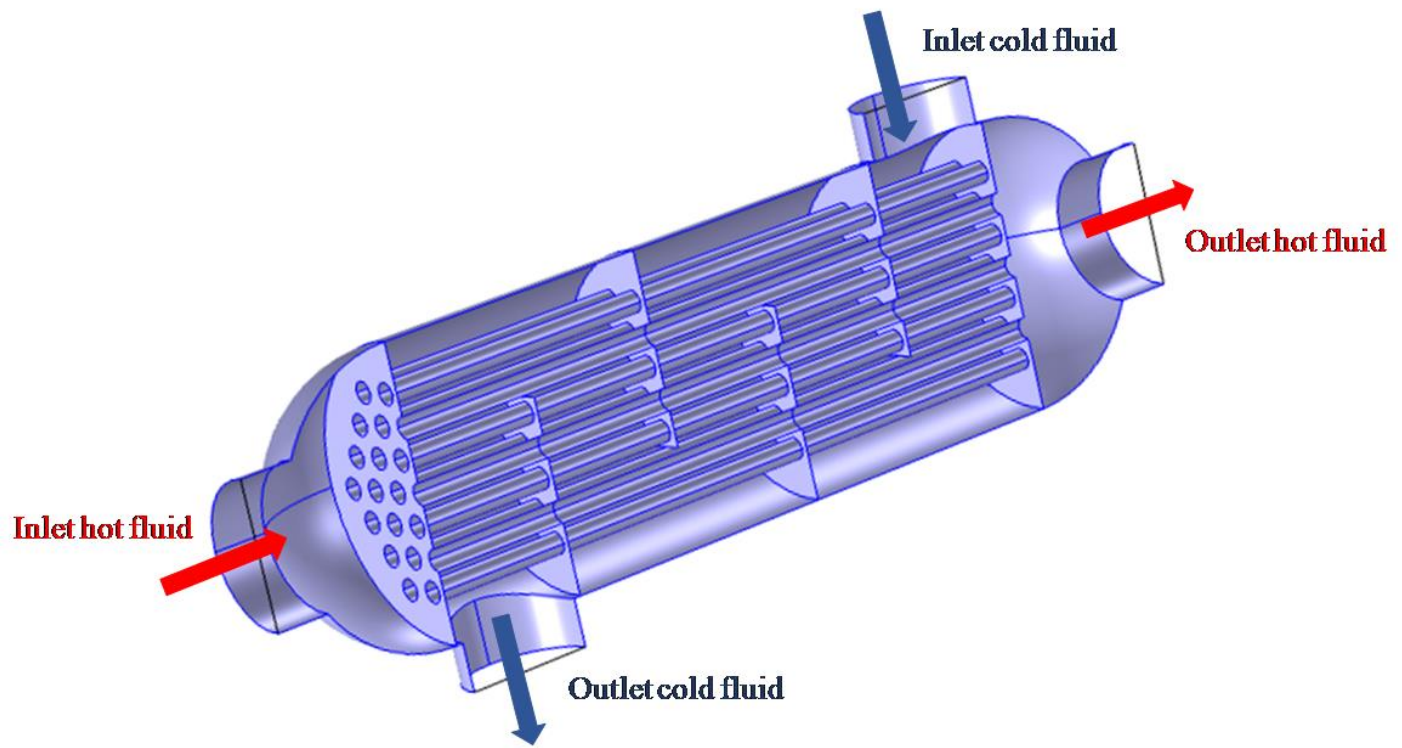

Fig. 1. Configuration of shell-and-tube heat exchanger model study 


\section{Governing Equations and Boundary Conditions}

The turbulent flow $k-\varepsilon$ model was used to solve the heat transfer and fluid flows characteristics of STHEs, the computational fluid is governed by the continuity, momentum, energy equations, as described below $[1,6]$

Continuity equation

$\nabla \cdot(\rho u)=0$

Momentum equation

$(\nabla \cdot u) \rho u=-\nabla p+\nabla \cdot \mu\left(\nabla u+(\nabla u)^{T}\right)$

Energy equation

$\rho C_{P} u(\nabla T)=\nabla \cdot(k \nabla T)+Q$

The $k-\varepsilon$ standard model of turbulence that is based on the energy dissipation $\varepsilon$ (Eq. (4)) and the turbulent kinetic energy $k$ (Eq. (5)) is used in this study.

$\rho(u . \nabla) \varepsilon=\nabla \cdot\left[\left(\mu+\frac{\mu T}{\sigma \varepsilon}\right) \nabla \varepsilon\right]+C_{e 1} \frac{\varepsilon}{k} P_{k}-C_{e 2} \rho \frac{\varepsilon^{2}}{k}, \varepsilon=e q$

$\rho(u . \nabla) k=\nabla \cdot\left[\left(\mu+\frac{\mu T}{\sigma k}\right) \nabla T\right]+P_{k}-\rho \varepsilon$

where the production term is

$P_{k}=\mu_{T}\left[\nabla u:\left(\nabla u+(\nabla u)^{T}\right)\right]$

The turbulent viscosity is modeled as

$\mu_{T}=\rho C_{\mu} \frac{k^{2}}{\varepsilon}$

The empirical constants for the standard k- $\varepsilon$ model are assigned the following values

$\mathrm{C}_{\mathrm{e} 1}=1.44, \mathrm{C}_{\mathrm{e} 2}=1.92, \mathrm{C}_{\mu}=0.09, \sigma_{\mathrm{k}}=1, \sigma_{\mathrm{e}}=1.3$

The pressure drop in the shell side can be obtained using the following equation $[17,18]$

$$
\begin{aligned}
& \Delta P=f \frac{D_{s}}{D_{e}}\left(N_{b}+1\right) \frac{1}{2} \rho V^{2} \\
& D_{e}=\frac{4\left(\frac{\sqrt{3} p_{t}^{2}}{4}-\frac{\pi d_{0}^{2}}{8}\right)}{\frac{\pi d_{0}}{2}}
\end{aligned}
$$


$R e_{s}=\frac{\rho u D_{e}}{\mu}$

The Nusselt number was obtained for all the studied cases using the Eq. (11)

$N u=\frac{h D}{k}$

The convective heat transfer coefficient of the shell and tube heat exchanger is calculated based on the following correlation

$h=\frac{Q}{A \times L M T D}$

where, $A$ is total heat transfer area (in $\mathrm{m}^{2}$ ), $\mathrm{Q}$ is heat transfer from hot stream into cold stream (in W), LMTD is logarithmic mean temperature difference, (in K).

$Q=V(\rho C p)_{n f}\left(T_{h 1}-T_{h 2}\right)$

where, $\mathrm{V}$ is volumetric flow rate, $\mathrm{m}^{3} / \mathrm{hr}, \mathrm{Th}_{1}, \mathrm{Th}_{2}$ are inlet and outlet temperatures of hot stream (tube side), ${ }^{\circ} \mathrm{C}$. The LMTD can be calculated as follows [19].

$L M T D=\frac{\left(T_{h 1}-T_{C 2}\right)-\left(T_{h 2}-T_{c 1}\right)}{\ln \frac{\left(T_{h 1}-T_{c 2}\right)}{\left(T_{h 2}-T_{c 1}\right)}}$

where, $T_{c 1}, T_{c 2}$ are inlet and outlet temperatures of cold stream (shell side) respectively.

\section{Thermo-Physical Properties of Nanofluids}

The thermo-physical properties of the nanofluid can be obtained from the following relations. The density of nanofluid which is assumed to be constant, where the relative viscosity of alumina nanofluid is expressed as

$\frac{\mu_{n f}}{\mu_{b f}}=1+4.93 c_{v}+222.4 c_{v}^{2}$

The density is expressed as

$\rho_{n f}=c_{v} \rho_{p}+\left(1-c_{v}\right) \rho_{b f}$

The thermal volume expansion of the nanofluid $\left(\rho_{n f} \beta_{n f}\right)$ is expressed as

$\rho_{n f} \beta_{n f}=\left(1-c_{v}\right) \rho_{b f} \beta_{b f}+c_{v} \rho_{p} \beta_{p}$

The ratio of the thermal conductivity of the nanofluid $\left(\mathrm{k}_{\mathrm{nf}}\right)$ on the thermal conductivity of the base fluid $\left(k_{b f}\right)$ is defined as below

$\frac{k_{n f}}{k_{b f}}=1+2.944 c_{v}+19.672 c_{v}^{2}$ 
The specific heat of the nanofluid is estimated as

$\rho_{n f} C p_{n f}=c_{v} \rho_{p} C p_{p}+\left(1-c_{v}\right) \rho_{b f} C p_{b f}$

where, $C \mathrm{p}_{\mathrm{nf}}$ is the specific heat of the nanofluid and $\mathrm{C} \mathrm{p}_{\mathrm{bf}}$ presents the specific heat of the base fluid. Therefore, for different values of concentration of the $\mathrm{Al}_{2} \mathrm{O}_{3}$ nanofluid, a summary of the corresponding thermophysical properties of the nanofluid suspension can be summarized in Table 2 [23]. Also, the thermophysical proprieties of water as a base fluid are given in Table 3.

Table 2

Thermophysical properties of $\mathrm{Al}_{2} \mathrm{O}_{3}$ / water for three different concentration of $\mathrm{Al}_{2} \mathrm{O}_{3}$

\begin{tabular}{llll}
\hline Thermophysical properties & $\mathrm{C}_{\mathrm{v}}=1 \%$ & $\mathrm{C}_{\mathrm{v}}=2 \%$ & $\mathrm{C}_{\mathrm{v}}=3 \%$ \\
\hline$\mu_{\mathrm{nf}}\left(\mathrm{kg} \cdot \mathrm{m}^{-1} \cdot \mathrm{s}^{-1}\right)$ & $1.073 \times 10^{-3}$ & $1.190 \times 10^{-3}$ & $1.350 \times 10^{-3}$ \\
$\rho_{\mathrm{nf}}\left(\mathrm{kg} \cdot \mathrm{m}^{-3}\right)$ & 1024.317 & 1050.334 & 1076.3510 \\
$\rho_{\mathrm{nf}} \beta_{\mathrm{nf}}\left(\mathrm{Kg} \cdot \mathrm{m}^{-3} \cdot \mathrm{K}^{-1}\right)$ & 0.20489 & 0.2031 & 0.2013 \\
$\mathrm{knf}_{\mathrm{nf}}\left(\mathrm{W} \cdot \mathrm{m}^{-1} \cdot \mathrm{K}^{-1}\right)$ & 0.61678 & 0.6379 & 0.6614 \\
$\rho_{\mathrm{nf}} \mathrm{C} \mathrm{p}_{\mathrm{nf}}\left(\mathrm{kg} \cdot \mathrm{kJ} \cdot \mathrm{m}^{-4} \cdot \mathrm{K}^{-1} \cdot \mathrm{s}^{-1}\right)$ & 4157.71 & 4143.53 & 4129.36 \\
\hline
\end{tabular}

Table 3

Thermophysical properties of the shell-and-tube heat exchanger side fluids

\begin{tabular}{lll}
\hline Thermophysical properties & Air & $\mathrm{C}_{\mathrm{v}}=2 \%$ \\
\hline density & $1.269\left(\mathrm{~kg} \cdot \mathrm{m}^{-3}\right)$ & $971.8\left(\mathrm{~kg} \cdot \mathrm{m}^{-3}\right)$ \\
thermal conductivity & $0.02401\left(\mathrm{~W} \cdot \mathrm{m}^{-1} \cdot \mathrm{K}^{-1}\right)$ & $0.6562\left(\mathrm{~W} \cdot \mathrm{m}^{-1} \cdot \mathrm{K}^{-1}\right)$ \\
specific heat capacity & $1006\left(\mathrm{~J} \cdot \mathrm{kg}^{-1} \cdot \mathrm{K}^{-1}\right)$ & $4194\left(\mathrm{~J} \cdot \mathrm{kg}^{-1} \cdot \mathrm{K}^{-1}\right)$ \\
dynamic viscosity & $0.00001754(\mathrm{~Pa} \cdot \mathrm{s})$ & $0.0003545(\mathrm{~Pa} . \mathrm{s})$ \\
Ration of specific heat & 1.4 & 1 \\
\hline
\end{tabular}

\subsection{Protocol of Evaluation and Optimization}

The evaluation of the $\mathrm{Al}_{2} \mathrm{O}_{3}$ nanofluid behaviours based on the comparison with the base fluid (water). For the heat transfer evaluation, overall convective heat transfer coefficient $(h)$ or Nusselt number $(\mathrm{Nu})$ are used to estimate heat transfer execution of the STHE. Friction factor $(f)$ is the parameter used to evaluate the pressure drop. In order to optimize the present system, thermal effectiveness, thermal efficiency of tube and shell sides are used as optimization parameters.

The thermal efficiency of the hot side $\eta_{\text {hot }}$ is the ratio of the temperature difference of the hot side to the maximum temperature difference between the hot and cold sides in a perfect heat exchanger [24].

$\eta_{h o t}=\frac{\left(T_{h 1}-T_{h 2}\right)}{\left(T_{h 1}-T_{C 1}\right)}$

Similarly, the thermal efficiency of the cold side $\eta_{\text {cold }}$ is the ratio of the temperature difference of the cold side to the maximum temperature difference between the hot and cold sides in a perfect heat exchanger.

$\eta_{\text {cold }}=\frac{\left(T_{c 2}-T_{c 1}\right)}{\left(T_{h 1}-T_{c 1}\right)}$

The mean thermal efficiency, $\eta_{\text {mean }}$. 
$\eta_{\text {mean }}=\frac{\eta_{\text {hot }}+\eta_{\text {cold }}}{2}$

\section{Procedure of Meshes Sensibility Test and Solver Settings}

The shell-and-tube heat exchanger geometry studied was shaped by using the CFD code COMSOL Multiphysics, version 5.4. Since, it is well suited to construct complex-shaped geometries, the tetrahedral elements that operate under the free tetrahedral elements have been used to mesh the computational domain, and this algorithm provides an unstructured mesh with variable element size, which allows us to make a denser mesh around the tubes and baffles (Figure 2). A series of generated meshes was realized on our numerical domain: 910879, 1.297.723, 1.454.659, 1.733 .365 and 2.000.114 elements. Starting of the case of 1.454 .659 elements, we observed that deviation of the Nusselt number results do not less than $1 \%$. Therefore, the mesh size of 1.454 .659 elements was chosen for the following investigations.

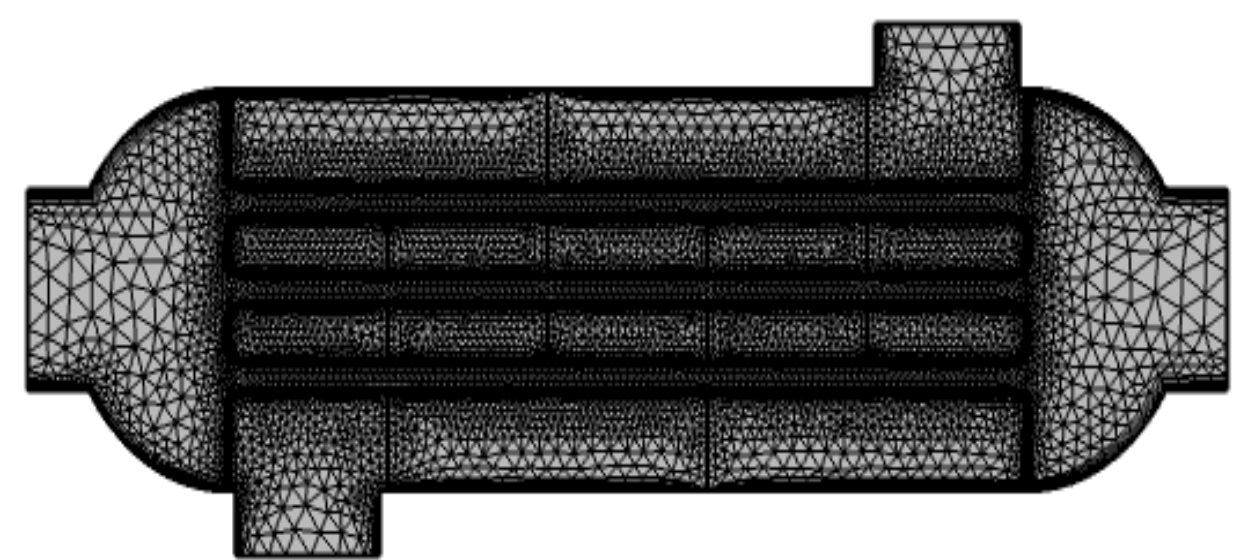

Fig. 2. Tetrahedral Mesh generated on the numerical domain of the shell-andtube heat exchanger

COMSOL Multiphysics 5.4 which is based on the finite element method, is the computer code used to analyse the fluid flow and heat transfer phenomena for the present study. Segregated solvers are used to solving the governing equations. The Generalized Minimal Residual (GMRES) iterative method solver is used to calculate the parameters with estimated factor error and tolerance of 20 and 0.001, respectively. The geometric Multi-grid solver is used with PARDISO (Parallel Sparse Direct Linear Solver) as a pre-conditioner. The numerical simulations were realized on a PC-i7 with a CPU frequency of $3.7 \mathrm{Go}$ and a RAM of $64 \mathrm{Go}$. A typical model of running time for calculation of one case is about seventeen hours.

\section{Results and Discussions}

\subsection{Validation of Numerical Model}

In order to check the reliability of the present numerical model, a validation of results is realized is this work as shown in Figure 3. Figure shows a comparison of the present results of pressure drop in STHE and which are reported in Ref [7] for the same conditions. Compared with the experimental and numerical results founded by Ref [7], our results showed maximum deviation of $9 \%$ and $6 \%$, respectively. So, a very satisfactory agreement was found from this comparison. 


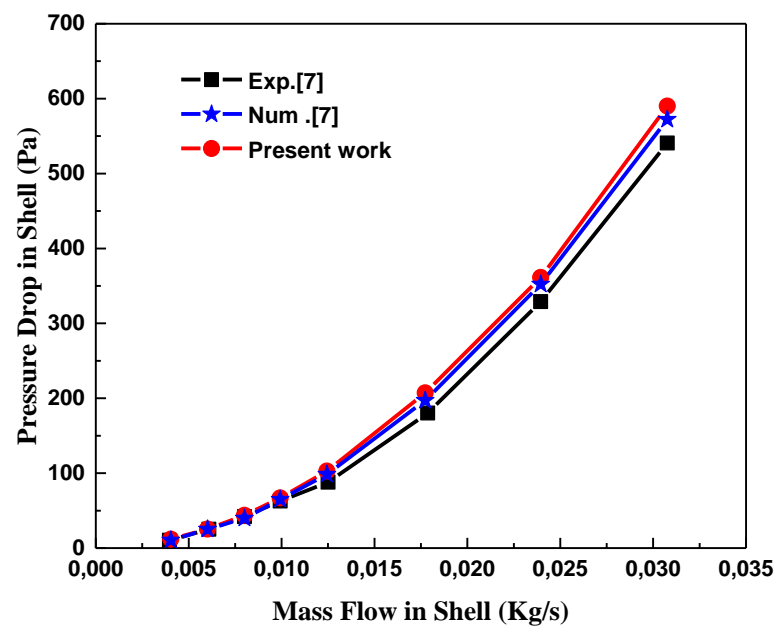

Fig. 3. Validation of results

\subsection{Heat Transfer}

The variation of the average Nusselt number $(\mathrm{Nu})$ according to all range of inlet velocity $(\mathrm{U})$ values is exposed in Figure 4 for the different concentrations $\left(C_{v}\right)$ of the $\mathrm{Al}_{2} \mathrm{O}_{3}$ nanoparticles $(\mathrm{Cv}=1 \%, 2 \%$, and $3 \%)$. The figure depicts and increase in Nusselt number ( $\mathrm{Nu}$ ) as inlet velocity (u) rises for all concentrations values $\left(C_{v}\right)$. Also, this figure shows an important difference between Nusselt numbers of the base fluid (water) and the concentrations values $\left(C_{v}\right)$ of the nanofluid, especially for $2 \%$ and $3 \%$.

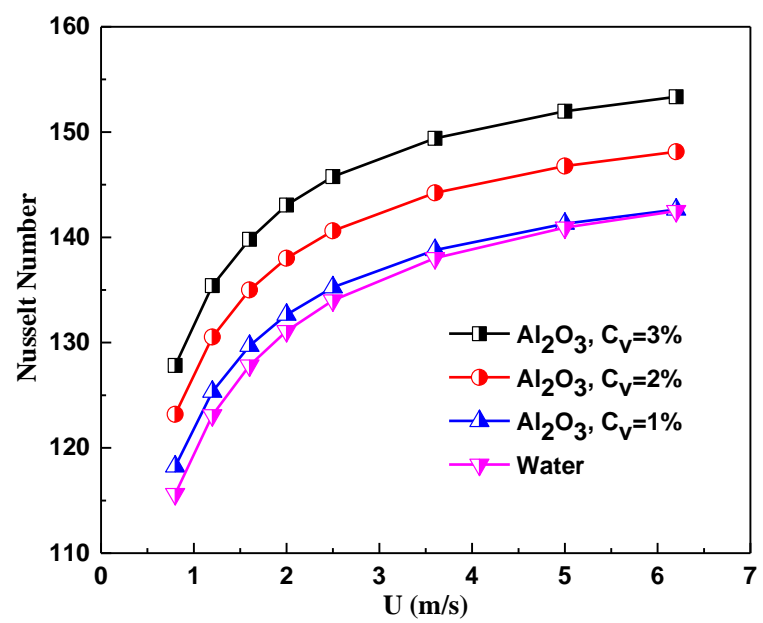

Fig. 4. Variation of the average Nusselt number

(Nu) vs. Inlet velocity (U)

Base fluid (water in the present study) always has the lowest heat transfer coefficients, due to the feeble thermo-physic proprieties (thermal conductivity, specific heat, and density). Thus, the addition of the nanoparticles on the base fluid clearly changes and improves the thermal execution of the nanofluids thermo-physic proprieties [34,35]. From the figure, Nusselt number increases versus inlet velocity rise. Also, Nusselt number is augmented according to of the increase of the fraction of the volume of the nanoparticles $\left(C_{v}\right)$ in the water (base fluid). These performances enhancement due to the augmentation of the inertial shears near the walls, and the improvement of the thermal conductivity of the nanofluid which are improving the convective heat transfer rates. At 
the highest velocity value $(\mathrm{U}=6.2 \mathrm{~m} / \mathrm{s})$, Nusselt numbers are augmented by $0.1 \%, 3.96 \%$ and $7.62 \%$ for $C_{v}=1 \%, 2 \%$ and $3 \%$, compared with base fluid respectively. This is qualified to the meaningfully better thermal properties of $\mathrm{Al}_{2} \mathrm{O}_{3}$ nanofluid with $3 \%$ of concentration $\left(\mathrm{C}_{\mathrm{v}}\right)$ which are: higher density, thermal conductivity, and specific heat capacity. In the thermal phenomenon, it exist a fundamental link between fluid flows and heat transfer. In addition to the nanoparticles effects, the effect of the baffles is also taking an important side in the STHE design. As illustrates in Figure 5, the zigzag and the change of directions of the fluid due to the presence of baffles helps to stop the apparitions of the boundary layers which are causes an augmentation of the velocity fluctuations and turbulence intensity and as a consequence are enhance the thermal performance of STHEs [36-38].

\subsection{Pressure Drop}

From Figure 5, the zigzag and the change in the directions of the fluid through the tubes and baffles not only augment the heat transfer rates but are also generating pressure drop penalty. Where, as any thermal system, the augmentation of heat transfer coefficients generally associates pressure drop penalty. Figure 6 presents the variation of the friction factor versus inlet velocity values for different values of $\mathrm{Al}_{2} \mathrm{O}_{3}$ nanoparticles concentration of $\left(\mathrm{C}_{\mathrm{v}}=1 \%, 2 \%\right.$ and $\left.3 \%\right)$. Firstly, the friction factor is decreased according to the rises in the inlet velocity due to the inertial shears augmentation near the walls which are reduce the effects of the hydrodynamic and thermal boundary layers. In addition, the presence of solid nanoparticles in the base fluid (water) is also helping to augment the pressure drop due to the increases in the viscosity of the nanofluid. From the same figure, and at the highest velocity value $(U=6.2 \mathrm{~m} / \mathrm{s})$, friction factor is increased by $22.41 \%, 24.14 \%$ and $26.72 \%$ for $C_{v}$ $=1 \%, 2 \%$ and $3 \%$ linked with the base fluid respectively.

\subsection{Thermal Efficiency Evaluation and Optimization}

This section presents an important part of the present study where thermal efficiency $(\eta)$ is the parameter which used to select a better thermal system. Figure 7(a) presents the variation of the thermal effectiveness of the nanofluid side of the shell ( $\left.\eta_{\text {cold }}\right)$ according to the speed at the entry of the nanofluid for various concentrations of $\mathrm{Al}_{2} \mathrm{O}_{3}$ nanofluid.

As speed increases, the effectiveness also increases. $\mathrm{Al}_{2} \mathrm{O}_{3}$ nanofluid with a higher concentration of $\mathrm{Al}_{2} \mathrm{O}_{3}$ has a coefficient more raised of thermal transfer who leads to an increase in the difference of the temperature between the inlet and outlet of the nanofluid on the shell-side. From Figure 7(b), for the hot side where the water flows inside the tube, the thermal efficiency ( $\eta_{\text {hot }}$ ) decreases according to the rises of the inlet speed of the hot fluid. Figure 7(c) shows the variation of the mean thermal efficiency $\left(\eta_{\text {mean }}\right)$ versus the inlet velocity $(U)$. $\left(\eta_{\text {mean }}\right)$ increases according to the rises in the inlet velocity $(U)$ and reach its greater value for the highest value of the $\mathrm{Al}_{2} \mathrm{O}_{3}$ nanofluid concentration $\left(C_{v}=1 \%\right)$. For the highest inlet speed value $(U=6.2 \mathrm{~m} / \mathrm{s})$ the mean thermal efficiency $\left(\eta_{\text {mean }}\right)$ is improved by $2 \%, 4 \%$, and $6 \% C_{v}=1 \%, 2 \%$, and $3 \%$ compared with the base fluid respectively. 


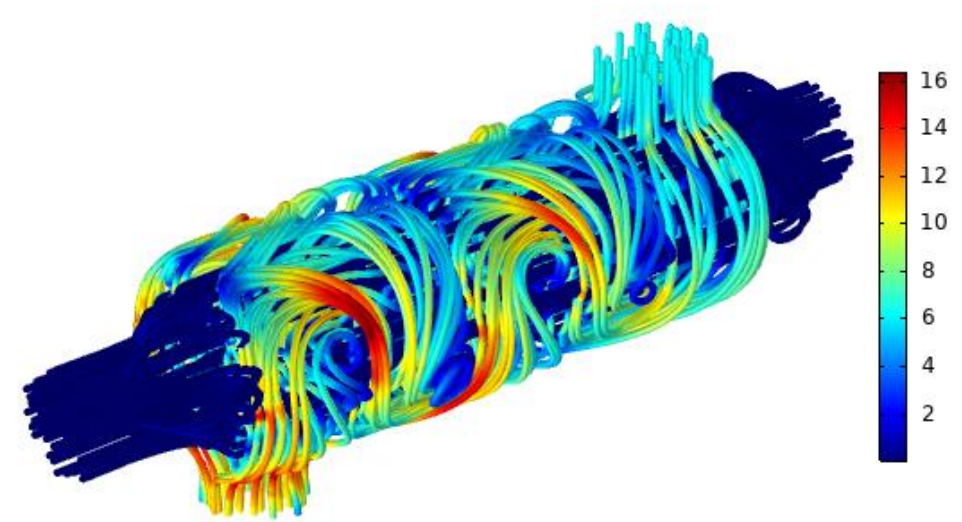

(a)

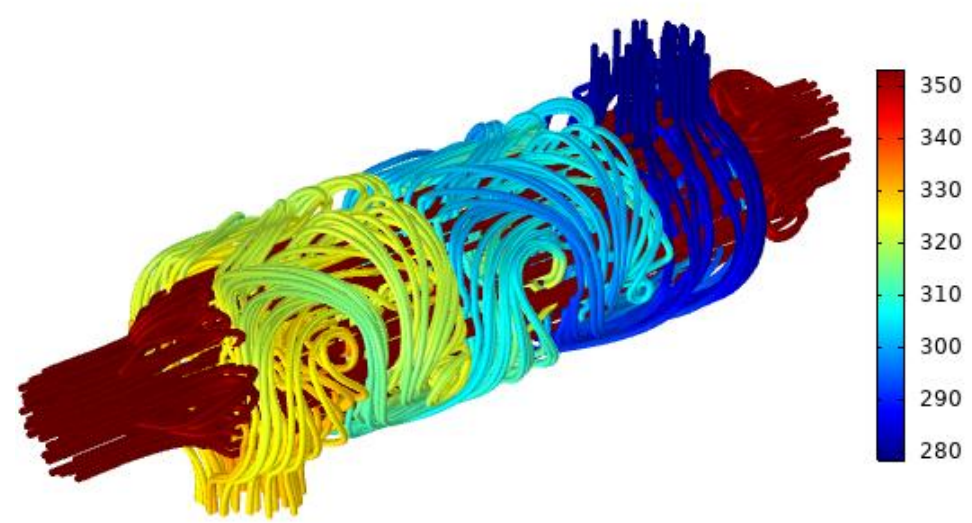

(b)

Fig. 5. Illustration of hydrodynamic and thermal aspects, (a) streamline velocity $(\mathrm{m} / \mathrm{s})$ and $(b)$ streamline temperature $(\mathrm{K})$ distributions, for $C_{v}=3 \%, U=6.2 \mathrm{~m} / \mathrm{s}$

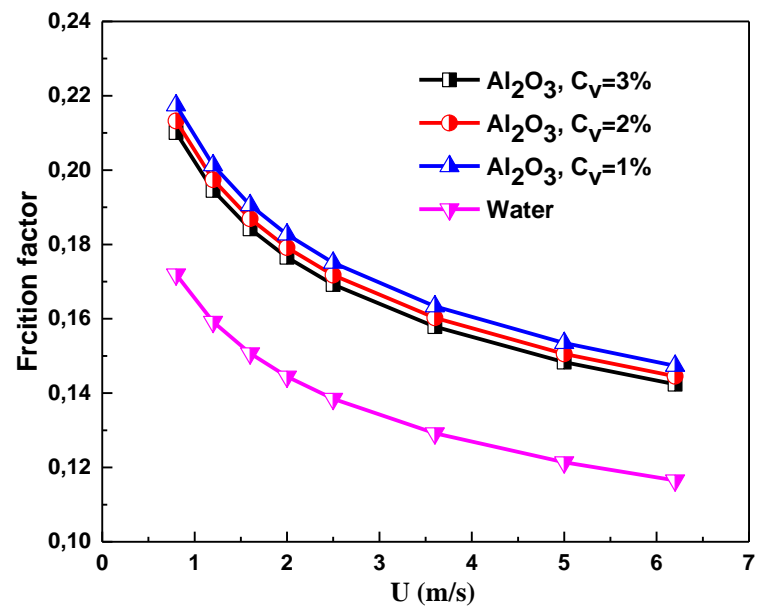

Fig. 6. Variation of the friction factor (f) vs. Inlet velocity (U) 


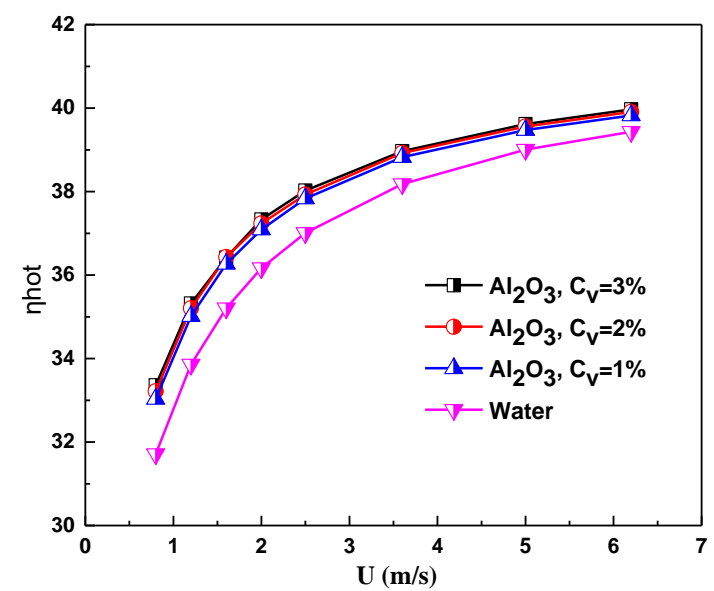

(a)

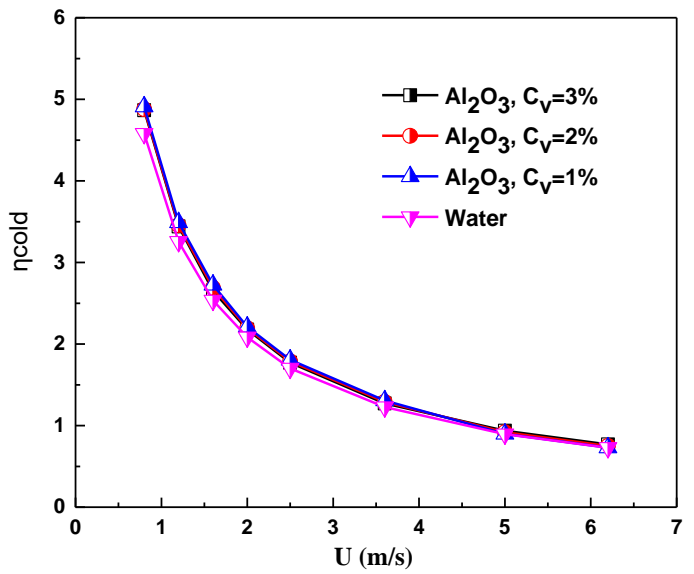

(b)

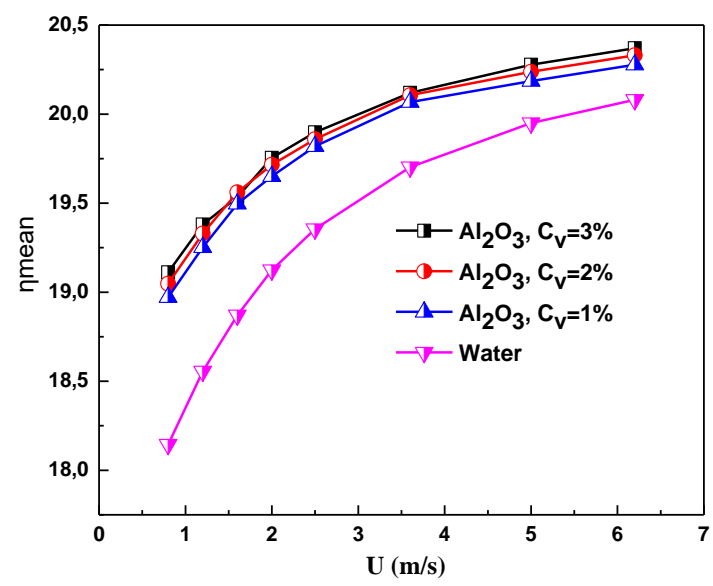

(c)

Fig. 7. Variation of the thermal performance factor ( $\eta$ ) vs. Inlet velocity (U) for (a) hot side, (b) cold side and (c) the mean factor

\section{Conclusions}

In this work, a numerical study was carried out to evaluate the characteristics of the fluids flows and heat transfer in STHEs. The effect of the combination between the baffles inserts and the $\mathrm{Al}_{2} \mathrm{O}_{3}$ nanofluid in STHEs was analysed. The hydro-thermal characteristics of baffled shell-and-tube heat exchanger using $\mathrm{Al}_{2} \mathrm{O}_{3}$ /water nanofluid for three different concentrations of $\mathrm{Al}_{2} \mathrm{O}_{3}$ nanoparticles were used (I.e. $C_{v}=1 \%, 2 \%$, and $3 \%$ ) are also studied by using CFD COMSOL 5.4. Compared with base fluid, the numerical results show the important role of nanofluids in the STHEs performance. Where, the heat transfer coefficients are augmented by $0.1 \%, 3.96 \%$ and $7.62 \%$ for $\mathrm{Cv}=1 \%, 2 \%$ and $3 \%$, respectively.

Also, the results show that the combination between nanofluids and baffling techniquein STHEs can become a promising strategy to enhance the heat transfer rates and reduce energy consumption. Where, for the highest inlet speed value $(U=6.2 \mathrm{~m} / \mathrm{s})$, the mean thermal efficiency $\left(\eta_{\text {mean }}\right)$ is improved by $6 \%$ for $\mathrm{C}_{v}=3 \%$ compared with the base fluid. 


\section{References}

[1] Mohammadi, Mohammad Hadi, Hamid Reza Abbasi, Adel Yavarinasab, and Hossein Pourrahmani. "Thermal optimization of shell and tube heat exchanger using porous baffles." Applied Thermal Engineering 170 (2020): 115005.

https://doi.org/10.1016/j.applthermaleng.2020.115005

[2] Raj, Karuppa Thundil R., and Srikanth Ganne. "Shell side numerical analysis of a shell and tube heat exchanger considering the effects of baffle inclination angle on fluid flow using CFD." Thermal Science 16, no. 4 (2012): 11651174. https://doi.org/10.2298/TSCI110330118R

[3] Zhou, Guo-Yan, Jingmei Xiao, Lingyun Zhu, Juntao Wang, and Shan-Tung Tu. "A numerical study on the shell-side turbulent heat transfer enhancement of shell-and-tube heat exchanger with trefoil-hole baffles." Energy Procedia 75 (2015): 3174-3179.

https://doi.org/10.1016/i.egypro.2015.07.656

[4] Kallannavar, Sachin, Suresh Mashyal, and Manik Rajangale. "Effect of tube layout on the performance of shell and tube heat exchangers." Materials Today: Proceedings 27 (2020): 263-267. https://doi.org/10.1016/i.matpr.2019.10.151

[5] Kern, Donald Quentin. Process heat transfer. Tata McGraw-Hill Education, 1997.

[6] Yehia, Mahmoud Galal, Ahmed AA Attia, Osama Ezzat Abdelatif, and Essam E. Khalil. "Heat transfer and friction characteristics of shell and tube heat exchanger with multi inserted swirl vanes." Applied Thermal Engineering 102 (2016): 1481-1491. https://doi.org/10.1016/i.applthermaleng.2016.03.095

[7] Saffarian, Mohammad Reza, Farivar Fazelpour, and Mehrzad Sham. "Numerical study of shell and tube heat exchanger with different cross-section tubes and combined tubes." International Journal of Energy and Environmental Engineering 10, no. 1 (2019): 33-46.

https://doi.org/10.1007/s40095-019-0297-9

[8] Labbadlia, O., B. Laribi, Boualem Chetti, and Patrick Hendrick. "Numerical study of the influence of tube arrangement on the flow distribution in the header of shell and tube heat exchangers." Applied thermal engineering 126 (2017): 315-321. https://doi.org/10.1016/i.applthermaleng.2017.07.184

[9] Qiu, Yu, Ming-Jia Li, Wen-Qi Wang, Bao-Cun Du, and Kun Wang. "An experimental study on the heat transfer performance of a prototype molten-salt rod baffle heat exchanger for concentrated solar power." Energy 156 (2018): 63-72.

https://doi.org/10.1016/i.energy.2018.05.040

[10] Mellal, Mustapha, Redouane Benzeguir, Djamel Sahel, and Houari Ameur. "Hydro-thermal shell-side performance evaluation of a shell and tube heat exchanger under different baffle arrangement and orientation." International Journal of Thermal Sciences 121 (2017): 138-149. https://doi.org/10.1016/i.ijthermalsci.2017.07.011

[11] Sahel, D., R. Benzeguir, and T. Baki. "Heat transfer enhancement in a fin and tube heat exchanger with isosceles vortex generators." Mechanics 21, no. 6 (2015): 457-464.

https://doi.org/10.5755/j01.mech.21.6.12240

[12] Sahel, Djamel, and Redouane Benzeguir. "Thermal characteristic in solar air heater fitted with plate baffles and heating corrugated surface." Energy Procedia 139 (2017): 307-314. https://doi.org/10.1016/j.egypro.2017.11.213

[13] Choi, Stephen US, and Jeffrey A. Eastman. Enhancing thermal conductivity of fluids with nanoparticles. No. ANL/MSD/CP-84938; CONF-951135-29. Argonne National Lab., IL (United States), 1995.

[14] Shin, Lee, Stephen, U. Choi, Sandy, S.C. Li. Jeffrey A.Eastman. "Measuring thermal conductivity of fluids containing oxide nanoparticles." Journal of Heat Transfer 121, (1999): 280-289.

https://doi.org/10.1115/1.2825978

[15] Xizwei, Wang, Xianfan Xu, Stephen, U. Choi. "Thermal conductivity of nanoparticle-fluid mixture." Journal of Thermophys Heat Transfer 13, (1999): 474-480. https://doi.org/10.2514/2.6486

[16] Ahmad, Hajatzadeh Pordanjani, Saeed Aghakhani, Masoud Afrand, Boshra Mahmoudi, Omid Mahian, Somchai Wongwises. "An updated review on application of nanofluids in heat exchangers for saving energy." Energy Conversion and Management 198, (2019): 111886.

https://doi.org/10.1016/i.enconman.2019.111886 
[17] Islam, Md. Shahrul, Mohammed Mahbubul Islam, Rahman Md. Saidur, Mohd Faizul Mohd Sabri, Sheikh Khaleduzzaman Shah. "Effectiveness study of a shell and tube heat exchanger operated with nanofluids at different mass flow rates." Numerical Heat Transfer 65, no. 7 (2014): 699-713.

https://doi.org/10.1080/10407782.2013.846196

[18] Öztop, Hakan F., Patrice Estellé, Wei-Mon Yan, Khaled Al-Salem, Jamel Orfi, and Omid Mahian. "A brief review of natural convection in enclosures under localized heating with and without nanofluids." International Communications in Heat and Mass Transfer 60, (2015): 37-44.

https://doi.org/10.1016/j.icheatmasstransfer.2014.11.001

[19] Shayan, M. Vanaki, Poo Balan Ganesan, Hussein A. Mohammed. "Numerical study of convective heat transfer of nano fluids: A review." Renewable and Sustainable Energy Reviews 54, (2016): 1212-1239.

https://doi.org/10.1016/i.rser.2015.10.042

[20] Minea, Alina Adriana. "Simulation of Nanofluids Turbulent Forced Convection at High Reynolds Number: A Comparison Study of Thermophysical Properties Influence on Heat Transfer Enhancement." Flow Turbulence Combustion 94, (2015): 555-575.

https://doi.org/10.1007/s10494-014-9590-0

[21] Farajollahi, B., S. Gh Etemad, and M. Hojjat. "Heat transfer of nanofluids in a shell and tube heat exchanger." International Journal of Heat and Mass Transfer 53, no. 1-3 (2010): 12-17.

https://doi.org/10.1016/i.ijheatmasstransfer.2009.10.019

[22] Nahian, Jaed Al, Partha Pratim Pandit, and Mohammad Arif Hasan Mamun. "Numerical study of a crossflow heat exchanger to investigate thermal performance using nanofluids." In AIP Conference Proceedings, vol. 2121, no. 1, p. 070020. AIP Publishing LLC, 2019.

https://doi.org/10.1063/1.5115927

[23] Menni, Younes, Ali J. Chamkha, and Houari Ameur. "Advances of nanofluids in heat exchangers -A review." Heat Transfer 49, no. 8 (2020): 4321-4349.

https://doi.org/10.1002/htj.21829

[24] Mahammedi, Abdelkader, Houari Ameur, Younes Menni, and Driss Meddah Medjahed. "Numerical Study of Turbulent Flows and Convective Heat Transfer of Al2O3-Water Nanofluids In A Circular Tube." Journal of Advanced Research in Fluid Mechanics and Thermal Sciences 77, no. 2 (2021): 1-12.

https://doi.org/10.37934/arfmts.77.2.112

[25] Fares, Mohammad, AL-Mayyahi Mohammad, and AL-Saad Mohammed. "Heat transfer analysis of a shell and tube heat exchanger operated with graphene nanofluids." Case Studies in Thermal Engineering 18 (2020): 100584. https://doi.org/10.1016/j.csite.2020.100584

[26] Salem, Mohamed R. "Experimental investigation on the hydrothermal attributes of MWCNT/water nanofluid in the shell-side of shell and semi-circular tubes heat exchanger." Applied Thermal Engineering (2020): 115438. https://doi.org/10.1016/i.applthermaleng.2020.115438

[27] Mojtaba, Bezaatpour, Hadi Rostamzadeh. "Heat transfer enhancement of a fin-and-tube compact heat exchanger by employing magnetite ferrofluid flow and an external magnetic field." Applied Thermal Engineering 164, (2019): 114462. https://doi.org/10.1016/j.applthermaleng.2019.114462

[28] M. Bezaatpour, Hadi Rostamzadeh, Javad Bezaatpour, Mohammea Ebadollahi. "Magnetic-induced nanoparticles and rotary tubes for energetic and exergetic performance improvement of compact heat exchangers." Powder Technology 377, (2021): 396-414.

https://doi.org/10.1016/i.powtec.2020.09.010

[29] M. Bezaatpour, Hadi Rostamzadeh. "Energetic and exergetic performance enhancement of heat exchangers via simultaneous use of nanofluid and magnetic swirling flow: A two-phase approach." Thermal Science and Engineering Progress 20, (2020): 100706. https://doi.org/10.1016/j.tsep.2020.100706

[30] Ke, Wang, Pengfei Wu, Zihua Tang, Li Liu, Jue Zhao, Ruinan Lin. "Flow patterns and pressure drop in the shell-andplate heat exchangers. " International Journal of Multiphase Flow 129, (2020): 103323. https://doi.org/10.1016/i.ijmultiphaseflow.2020.103323

[31] Ali, Abbas, Howard Lee, Akash Sengupta, Chi-Chuan Wang. "Numerical investigation of thermal and hydraulic performance of shell and plate heat exchanger." Applied Thermal Engineering 167, (2020): 114705. https://doi.org/10.1016/i.applthermaleng.2019.114705

[32] Gabriela, Huminic, Angel Huminic. "Entropy generation of nanofluid and hybrid nanofluid flow in thermal systems: A review." Journal of Molecular Liquids 302, (2020): 112533. https://doi.org/10.1016/i.molliq.2020.112533 
[33] Edward, S. Gaddis, Volker Gnielinski. "Pressure drop on the shell side of shell-and-tube heat exchangers with segmental baffles." Chemical Engineering Processes 36, no. 2, (1997): 149-159.

https://doi.org/10.1016/S0255-2701(96)04194-3

[34] Ziye, Ling, Zhenbin He, Tao xu, Xiaoming Fang, Xuenong Gao, Zzg Zhengguo Zhang. "Numerical investigation on performance comparison of non-Newtonian fluid flow in vertical heat exchangers combined helical baffle with elliptic and circular tubes." Applied Thermal Engineering 100, (2016): 84-97. https://doi.org/10.1016/i.applthermaleng.2016.02.033

[35] Arun, Kumar Tiwari, Pradyumna Ghosh, Jahar Sarkar. "Particles concentration levels of various nanofluids in plate heat exchanger for best performance." Internatiaonal Journal of Heat and Mass Transfer 89, (2015): 1110-1118. https://doi.org/10.1016/i.ijheatmasstransfer.2015.05.118

[36] Ahadi, Amirhossein, Sylvie Antoun, M. Ziad Saghir, and John Swift. "Computational fluid dynamic evaluation of heat transfer enhancement in microchannel solar collectors sustained by alumina nanofluid." Energy Storage 1, no. 2 (2019): e37. https://doi.org/10.1002/est2.37

[37] Yousfi, Aissa, Djamel Sahel, and Mustapha Mellal. "Effects of A Pyramidal Pin Fins on CPU Heat Sink Performances." Journal of Advanced Research in Fluid Mechanics and Thermal Sciences 63, no. 2 (2019): 260-273

[38] Haziqatulhanis, Ibrahim, Norazlianie Sazali , Ahmad Syahiman Mohd Shah, Mohamad Shaiful Abdul Karim ,Farhana Aziz , Wan Norharyati Wan Salleh. "A Review on Factors Affecting Heat Transfer Efficiency of Nanofluids for Application in Plate Heat Exchanger." Journal of Advanced Research in Fluid Mechanics and Thermal Sciences 60, no. 1 (2019): 144-154. 